\title{
Response of Cytokines and Hydrogen Peroxide to Sporothrix schenckii Exoantigen in Systemic Experimental Infection
}

\author{
Danielle Cardoso Geraldo Maia • Amanda Costa Gonçalves • Lucas Souza Ferreira • \\ Francine Alessandra Manente - Deivys Leandro Portuondo · José Carlos Rebuglio Vellosa • \\ Marisa Campos Polesi · Alexander Batista-Duharte $\cdot$ Iracilda Zeppone Carlos
}

Received: 21 July 2015/ Accepted: 4 November 2015/Published online: 24 November 2015

(C) Springer Science+Business Media Dordrecht 2015

\begin{abstract}
The response of hydrogen peroxide $\left(\mathrm{H}_{2} \mathrm{O}_{2}\right)$ and cytokines during an experimental sporotrichosis in male Swiss mice was assessed over a period of 10 weeks by monitoring macrophage activation challenged with exoantigen (ExoAg) from the fungus Sporothrix schenckii. The studied endpoints were: $\mathrm{H}_{2} \mathrm{O}_{2}$ production, fungal burden at spleen, apoptosis in peritoneal macrophages, and IL-1 $\beta$, IL-6, IL-2, IL-10 production. During the two first weeks of infection was observed low burden of yeast in spleen and high response of $\mathrm{H}_{2} \mathrm{O}_{2}$, IL-2, and IL-1 $\beta$. The weeks of highest fungal burden (fourth-sixth) coincided with major apoptosis in peritoneal macrophages, normal
\end{abstract}

D. C. G. Maia · A. C. Gonçalves - L. S. Ferreira •

F. A. Manente - D. L. Portuondo - J. C. R. Vellosa

M. C. Polesi - A. Batista-Duharte - I. Z. Carlos ( $₫)$

Departamento de Análises Clínicas, Faculdade de

Ciências Farmacêuticas de Araraquara, Universidade

Estadual Paulista "Júlio de Mesquita Filho" - UNESP,

Rua Expedicionários do Brasil $n^{\circ} 1621$, Araraquara,

SP CEP 14.801-902, Brazil

e-mail: carlosiz@fcfar.unesp.br

J. C. R. Vellosa

Departamento de Análises Clínicas e Toxicológicas, Setor de Ciências Biológicas e da Saúde, Universidade Estadual de Ponta Grossa - UEPG, Ponta Grossa, PR, Brazil

\section{A. Batista-Duharte}

Immunotoxicology Laboratory, Toxicology and

Biomedicine Center (TOXIMED), Medical Science

University, Autopista Nacional Km. 1 1/2,

90400 Santiago de Cuba, Cuba production of IL-6 and lower production of $\mathrm{H}_{2} \mathrm{O}_{2}$, IL2 , and IL-1 $\beta$, suggesting a role for these three last in the early control of infection. On the other hand, IL-1 $\beta$ (but not IL-6) was recovered since the sixth week, suggesting a possible role in the late phase of infection, contributing to the fungal clearance in conjunction with the specific mechanisms. The IL-10 was elevated until the sixth, principally in the second week. These results evidences that ExoAg is involved in the host immune modulation, influencing the $S$. Schenckii virulence, and its role is related with the time of the infection in the model used.

Keywords S. schenckii - Exoantigen - Macrophage · Hydrogen peroxide · Pro-inflammatory cytokines . Apoptosis

\section{Introduction}

Sporotrichosis is a mycosis that affects humans and animals, caused by the traumatic inoculation of the dimorphic fungus Sporothrix schenckii, recently cleared as component of a complex related to several cryptic infectious species (i.e., S. albicans, $S$. brasiliensis, S. globosa, S. luriei, S. mexicana, and Sporothrix schenckii sensu stricto) by molecular and phenotypic studies [1]. The disease is considered an emerging health problem, classically characterized by lesions of cutaneous and subcutaneous tissues with regional lymphocutaneous dissemination, although, 
pulmonary and systemic infections may also occur [2].The extent of the disease varies with size and depth of the initial inoculum, and with the immune status of the host [3]. The observation that sporotrichosis is more severe, and usually disseminated, in nude mice [4] and in patients with acquired immune deficiency syndrome suggests that $\mathrm{T}$ cell-mediated immunity is important to limit the extent of infection [5].

Macrophages are important effectors cells in the immune response against different fungus, mediating phagocytosis and the release of toxic agents, such as reactive oxygen and nitrogen intermediates [6]. The pathogen recognition and activation of macrophages largely depends on a family of pattern recognition receptor (PRRs) as Toll-like receptors (TLRs), which are regarded the major innate recognition system for microbial invaders in vertebrates and they are involved in the recognition and immunity against fungal infection [7]. Recently, our group reported that TLR-2 [8, 9], TLR-4 [10, 11] and intracellular caspase 1 inflammasome [12] are key molecules involved in macrophages activation during the innate immune response to $S$. schenckii infection. In these and other studies, were evaluated the stimulation of macrophages by major components of the fungal wall cells. However, in a pioneer in vitro experiment developed in our laboratory was observed that other component released in the $S$. schenckii culture, named exoantigen (ExoAg), a complex mixture containing the peptidorhamnomannan, composed by $33.5 \%$ rhamnose, $57 \%$ mannose, and $14.2 \%$ protein, was able of inhibit the phagocytic process with very low liberation of NO and TNF-alpha in macrophage cultures in comparison with components of the fungal wall [13]. This intriguing result supports a possible role of ExoAg in the virulence of $S$. schenckii [14]. In this way, Fernandes et al. [15] reported a possible association between virulence profile, ExoAg secretion, and immunogenicity of different $S$. schenckii isolates. However, even is insufficiently known the role of ExoAg released for this fungi during the infectious process.

The aim of this study was to investigate the dynamic in the production of hydrogen peroxide $\left(\mathrm{H}_{2} \mathrm{O}_{2}\right)$ IL-1 $\beta$, IL- 6 by macrophages, and IL-2, IL-10 by lymphocytes, during a murine infection by $S$. schenckii and the effect of ExoAg in this process.

\section{Materials and Methods}

Animals

Male Swiss mice (6-8 weeks old, weighing 18-25 g) were obtained from the Animal House at the School of Pharmaceutical Sciences, UNESP (Araraquara, SP, Brazil), and maintained under specific pathogen-free conditions, with water and food available ad libitum in proper Animal Houses. At least five animals were used for each experiment. All procedures were approved by the Ethics in Research Committee of the São Paulo State University - UNESP and are in accordance with the National Institutes of Health Animal Care Guidelines (CEP/FCF/CAr $n^{\circ}$ 14/2009).

\section{Microorganisms and Culture Conditions}

S. schenckii, strain 1099-18, was kindly provided by Dr Celuta Sales Alviano, Institute of Microbiology, Federal University of Rio de Janeiro, RJ, Brazil. This strain was isolated from a human case of sporotrichosis and phenotypically characterized at the Mycology Section of the Department of Dermatology, Columbia University, New York, NY. The fungus was cultured at $37^{\circ} \mathrm{C}$ for 8 days in brain-heart infusion broth (DIFCO Laboratories, Detroit, MI) with constant rotary shaking at 150 cycles/min, resulting in a suspension of yeast cells.

\section{Exoantigen (ExoAg) Derivation}

The fungus cultured as described above was submitted to UV radiation for $1 \mathrm{~h}$. This culture was shaken at $37^{\circ} \mathrm{C}$ for $24 \mathrm{~h}$ and then UVirradiated again for $1 \mathrm{~h}$. After this procedure, merthiolate was added to the culture medium at $1 / 5000$ concentration, and the culture was frozen at $-20{ }^{\circ} \mathrm{C}$ for $48 \mathrm{~h}$. Next, culture sterility was tested by the Sabouraud agar test, and the culture was filtered and concentrated 50-100 times in a concentrator (Amicon 8050, Danvers, MA). Protein was measured by the Lowry method, 1951 [16], and the protein composition was confirmed by Polyacrylamide Gel. 
Polyacrylamide Gel Electrophoresis (PAGE) of ExoAg from S. schenckii

The one-dimensional gel electrophoresis was performed basically as described by Laemmli in 1970, with minor modifications. The antigen samples (containing $50 \mu \mathrm{g}$ of protein) were resuspended in Line Marker Reducing sample buffer (Thermo Fisher Scientific, USA) and boiled for $5 \mathrm{~min}$. Following, the protein samples were electrophoresed on $10 \%$ polyacrylamide mini gel using a vertical slab gel apparatus (Thermo Fisher Scientific, USA) at a constant voltage of $100 \mathrm{~V}$ for $2 \mathrm{~h}$. As standards, the PageRuler Plus prestained protein ladder (Thermo Fisher Scientific, USA) was used. The protein bands were visualized using silver staining.

\section{Infection Method}

The animal infection with $S$. schenckii was carried out with a yeast suspension in phosphate-buffered saline (PBS, pH 7.4), containing $10^{7}$ cells $/ \mathrm{mL}$. Each animal was inoculated intraperitoneally with $100 \mu \mathrm{L}$ of this suspension in the experimental group, while animals in the control group were injected with PBS. Mice were euthanized in a $\mathrm{CO}_{2}$ chamber at different weeks after infection, and peritoneal cells of infected animals and control group were collected and re-stimulated in vitro with the Exo extract of $S$. schenckii yeast form. The groups were studied over a period of 10 weeks of infection.

Peritoneal Macrophages and Cells from Lymph Nodes

Thioglycollate-elicited peritoneal exudate cells (PECs) were harvested from Swiss mice using $500 \mu \mathrm{L}$ of sterile phosphate-buffered saline (PBS), $\mathrm{pH}$ 7.4. The cells were washed twice by centrifugation at $200 \times \mathrm{g}$ for $5 \mathrm{~min}$ at $4{ }^{\circ} \mathrm{C}$ and resuspended in appropriate medium for each test.

Cells from lymph nodes were also aseptically removed and passed through a $100-\mu \mathrm{m}$ cell strainer into a Petri dish containing $2 \mathrm{~mL}$ of PBS with the aid of a syringe plunger. The cells were then separated from the supernatant by centrifugation at $300 \times g$ for 5 min at $4{ }^{\circ} \mathrm{C}$, washed once with $3 \mathrm{~mL}$ of RPMI complete medium and then resuspended in $1 \mathrm{~mL}$ of the same medium. Cell concentration was determined by microscopy using the Trypan blue exclusion test and then they were adjusted to $5 \times 10^{6}$ cells $/ \mathrm{mL}$ in RPMI complete medium.

\section{Determination of Fungal Burden}

The spleen was removed aseptically and macerated with sterile PBS. A $200 \mu \mathrm{L}$ aliquot of this suspension was spread-plated on Sabouraud Agar medium in Petri dishes. Serial dilutions of $10^{-1}$ and $10^{-2}$ were also prepared and plated. The material was incubated for 5-7 days at room temperature, and the number of colonies formed on each plate (CFU) was counted, and the mean of viable fungi was then calculated for each group.

\section{Flow Cytometry Analysis of Apoptotic Cells}

The PECs were resuspended in RPMI 1640-C at a concentration of $2 \times 10^{6}$ cells $/ \mathrm{mL}$, and the adherent cells were obtained by a 1-h incubation at $37 \mathrm{C}$ in an atmosphere with $5 \% \mathrm{CO}_{2}$ (Forma Scientific). After this period, FLICA reagent (FAM-YVAD-fmk FLICATM Kit, Immunochemistry Technologies, Bloomington, MN, USA) was used to determine the percentage of apoptotic cells by flow cytometry, according to the manufacturer's instructions. The percentage of apoptotic cells was detected by flow cytometry with a FACSCanto flow cytometer and FACSDiva software (BD Biosciences, San Jose, CA, USA).

Hydrogen Peroxide Measurement

PECs $\left(2 \times 10^{6}\right.$ cells $\left./ \mathrm{mL}\right)$, harvested as described above, were suspended in a solution containing $140 \mathrm{mM} \mathrm{NaCl}, 10 \mathrm{mM}$ potassium phosphate buffer, $\mathrm{pH} 7.0,5.5 \mathrm{mM}$ dextrose, $0.56 \mathrm{mM}$ phenol red, and $0.01 \mathrm{mg} / \mathrm{mL}$ type II horseradish peroxidase. Aliquots of $100 \mu \mathrm{L}$ of this suspension were added to the wells of a 96-well flat-bottomed tissue-culture plate and supplemented with $50 \mu \mathrm{l}$ of $47.40 \mu \mathrm{g} / \mathrm{mL}$ ExoAg or $2 \times 10^{-5} \mathrm{M}$ of phorbol myristate acetate (PMA, Sigma, St. Louis, MO) or phosphate-buffered saline (PBS) for control wells. The cells were incubated for $1 \mathrm{~h}$ at $37{ }^{\circ} \mathrm{C}$ in a mixture of $95 \%$ air and $5 \% \mathrm{CO}_{2}$. The reaction was interrupted with $50 \mu \mathrm{l}$ of $4 \mathrm{~N} \mathrm{NaOH}$, and the samples were read at $620 \mathrm{~nm}$ against a blank containing phenol red solution and $4 \mathrm{~N} \mathrm{NaOH}$. The results were expressed as nmols of $\mathrm{H}_{2} \mathrm{O}_{2}$ per $2 \times 10^{5}$ 
cells, calibrated against solutions of known $\mathrm{H}_{2} \mathrm{O}_{2}$ concentration. At least four experiments were used for the test $[17,18]$.

\section{Cytokine Detection in Culture Supernatant}

PECs and cells from lymph nodes $\left(5 \times 10^{6}\right.$ cells $\left./ \mathrm{mL}\right)$, harvested as described above, were cultured overnight in RPMI 1640-C (with $100 \mathrm{U} / \mathrm{mL}$ penicillin, $100 \mu \mathrm{g}$ / $\mathrm{mL}$ streptomycin, $5 \times 10^{-2} \mathrm{M}$ mercaptoethanol and $5 \%$ inactivated fetal calf serum, designated RPMI 1640-complete (C) medium) at $37{ }^{\circ} \mathrm{C}$ under $5 \% \mathrm{CO}_{2}$. The culture media contained $47.40 \mu \mathrm{g} / \mathrm{mL}$ ExoAg, $10 \mu \mathrm{g} / \mathrm{mL}$ LPS (positive control for PEC) or $0.25 \mu \mathrm{g} /$ $\mathrm{mL}$ Concanavalin A (positive control for lymph nodes, and RPMI 1640-C (negative control), to stimulate production of cytokines IL- 6 and IL- $1 \beta$ by PEC and IL-2 and IL-10 by lymph nodes. Cytokines released into the supernatant of these cell cultures were quantified by enzyme-linked immunosorbent assay (ELISA) performed in 96-well plates according to manufacturer guidance (Kit DuoSet ${ }^{\circledR}, \mathrm{R} \& D$ Systems, Minneapolis, MN). Absorbance was read at $450 \mathrm{~nm}$ on a Multiskan Ascent ELISA microplate reader (Thermo Labsystems, Finland). The results were expressed in picograms $/ \mathrm{mL}$.

\section{Statistical Analysis}

Tukey's test was used for statistical comparison between experimental groups. Significance was declared at $p<0.001$. Data reported are representative of three independent experiments and are presented as the mean $\pm \mathrm{SD}$ of quadruplicate or triplicate observations $(n=12)$. Data were analyzed statistically by the program GraphPad InStat.

\section{Results}

Polyacrylamide Gel Electrophoresis (PAGE) of ExoAg from S. schenckii

Figure 1 shows the profile of proteins secreted as part of the ExoAg released by the fungus in the culture. The gels show several protein bands with different molecular weights ranging in size from 250 to $10 \mathrm{kDa}$.
Fig. 1 Protein profile of exoantigen (ExoAg) from S. schenckii. S. schenckii strain 1099-18 was cultured at $37{ }^{\circ} \mathrm{C}$ for 8 days in brainheart infusion broth. ExoAg pattern was obtained by onedimensional gel electrophoresis (lane 2) compared with and the molecular masses (in $\mathrm{kDa}$ ) of standard proteins (lane 1)

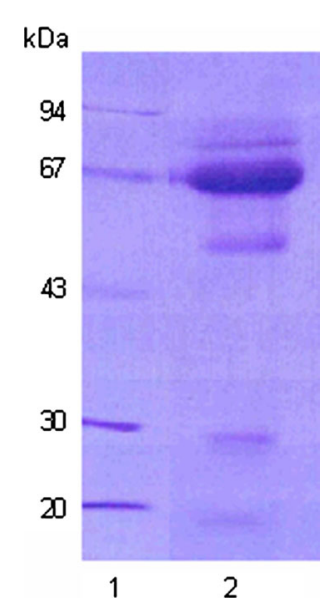

Determination of Fungal Burden

Interestingly, in this experiment while the $\mathrm{H}_{2} \mathrm{O}_{2}$ was elevated in the two first weeks of infection, the fungal burden in the spleen was diminished. Nevertheless, after that, it was found a pathogen's survival enhancing during the 4-6 weeks of infection, when a significant number of $S$. schenckii colonies were recovered (Fig. 2). However, the fungus recovered from the spleen was reduced significantly in the late phase of $S$. schenckii infection (eighth-tenth weeks).

\section{Determination of Apoptosis in PECs}

The apoptosis percentage was elevated in infected animals when compared with uninfected animals by all weeks of study. However, between the fourth and

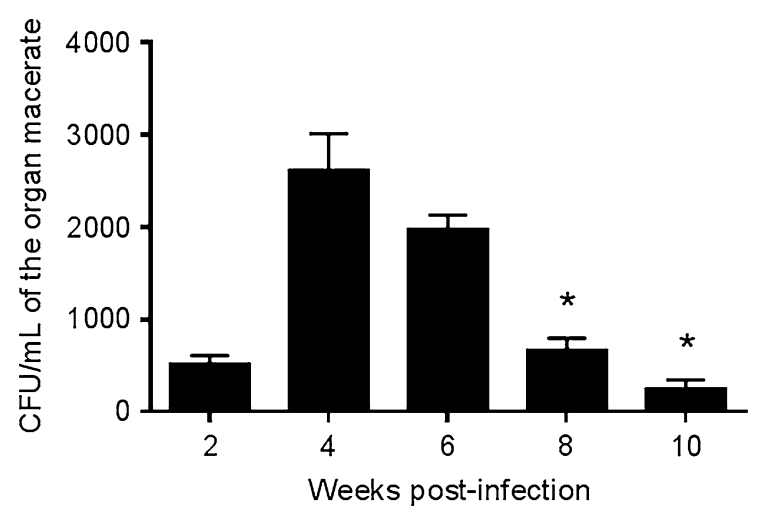

Fig. 2 Fungal burden (CFU/mL). Culture of microorganisms from spleen of animals infected through 2, 4, 6, 8 and 10 weeks. Vertical bars represent Mean $\pm \mathrm{SD} ; * p<0.001$ when compared to the fourth and sixth weeks (Tukey's test) 


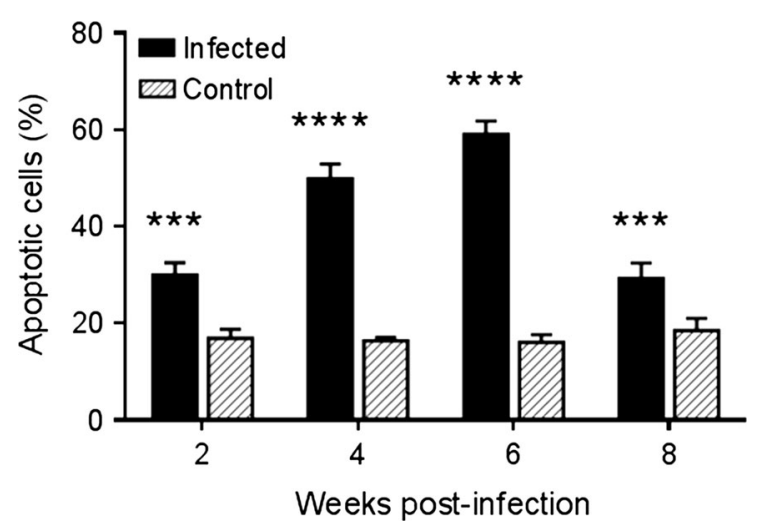

Fig. 3 Apoptosis in PECs from infected and uninfected with the fungus $S$. schenckii. In peritoneal exudate cells, after adhesion, of infected and uninfected mice the apoptosis was quantified by flow cytometry technique by determining FLICA and propidium iodide (PI). These results show values of three independent experiments. The results were expressed as percentage of cells undergoing apoptosis as mean \pm SD of five animals each week of infection $(* * * p<0.001, * * * * p<0.0001$ when compared to uninfected mice)

sixth weeks of infection were observed significantly higher percent of apoptosis in comparison with the others weeks (Fig. 3).

\section{Hydrogen Peroxide Measurement}

In an attempt to understand the immune response during sporotrichosis, and to know the role of ExoAg released by $S$. schenckii, it was investigated the oxidative burst through monitoring of $\mathrm{H}_{2} \mathrm{O}_{2}$ production by PECs from infected or not infected animals stimulated by ExoAg. PECs from uninfected animals cultured and stimulated with PMA, but not with ExoAg, produced $\mathrm{H}_{2} \mathrm{O}_{2}$ throughout the studied period. On the other hand, both PMA and ExoAg stimulated $\mathrm{H}_{2} \mathrm{O}_{2}$ production by macrophages from infected animals in the second week post-infection. After that, ExoAg was unable to stimulate the $\mathrm{H}_{2} \mathrm{O}_{2}$ production, suggesting that the oxidative burst is stimulated by the ExoAg in the initial phase of S. schenckii infection with a withdrawal of this innate defensive mechanism in late stages of sporotrichosis (Fig. 4).

\section{Cytokine Detection in Culture Supernatant}

The ability of PECs to produce IL- 6 and IL- $1 \beta$ was assayed too. Cells from uninfected animals (control group) produced IL-6 throughout the period, against
LPS or ExoAg stimuli, while macrophages from infected animals produced IL-6 throughout the studied period; however, this production was less pronounced before the fourth and after the sixth week of infection (Fig. 5a). In contrast, in the infected mice, IL-1 $\beta$ was falling since the second week until a lower concentration at sixth week. After that it was observed a slight increment in the subsequent weeks, while in noninfected mice, there were not observed significant changes in IL-1 $\beta$ production during the evaluated time (Fig. 5b).

On the other hand, both IL-2 and IL-10 secreted by lymphocytes were initially elevated in the second week (Fig. 6a and b, respectively). After that, they were decreasing their production in the ulterior weeks in infected animals when stimulated by the ExoAg. Interestingly, ExoAg stimulated the IL-10 production more that ConA in the second week and sixth weeks (Fig. 6b). In non-infected mice, there were not also observed changes in the IL-2 and IL-10 regarding to the evaluated period.

\section{Discussion}

S. schenckii is a complex of environmental pathogenic and opportunistic fungi that affect humans and different domestic animals causing subcutaneous or rarely systemic infections. This pathogen has diverse virulence factor facilitating the environmental resistance and the host invasion [19]. ExoAg is a soluble component released in the culture media of $S$. schenckii $[14,20]$. Although there are evidences of a possible role in the fungal virulence [14], even little is known about their role in the modulation of the immunity during the infectious process.

Host-fungus interactions are complex and dynamic, nd, once the fungi invade host cell, a series immunological mechanisms are activated, where the macrophages and the Th17 response are involved in the early fungal elimination [21, 22]. Activated macrophages release pro-inflammatory cytokines such as IL- $1 \beta$ and IL- 6 and produce nitrogen and oxygen reactive species, such as nitric oxide (NO) and $\mathrm{H}_{2} \mathrm{O}_{2}$, that together participate in the elimination of the invading pathogen [14], but also these innate mechanisms can produce deleterious effects if they are strongly activated [23-26]. Thus, other cytokines of the specific immunity can participate in the control of 
Experimental group

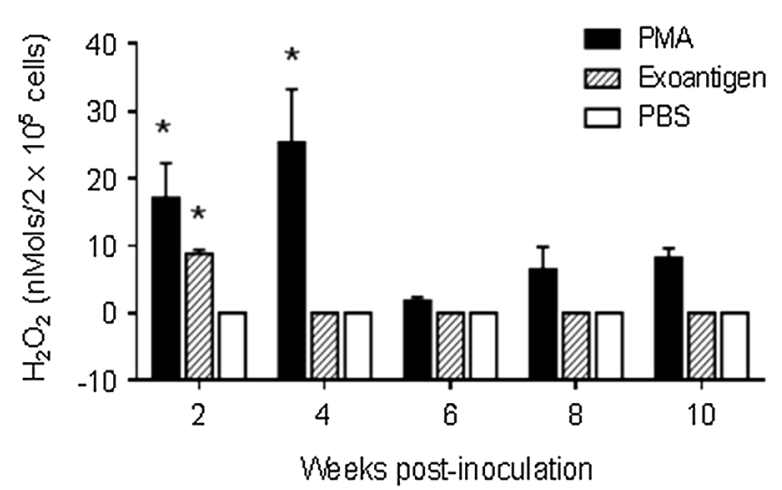

Fig. 4 Reactive oxygen intermediate induced during $S$. schenckii infection. Peritoneal exudate cells (PECs) $\left(2 \times 10^{6}\right.$ cells $/ \mathrm{mL}$ ) were cultured with exoantigen (ExoAg), PMA or PBS. After $1 \mathrm{~h}$ incubation at $37^{\circ} \mathrm{C}$ in a mixture of $95 \%$ air and $5 \% \mathrm{CO}_{2}$, the reaction was interrupted with $50 \mu \mathrm{L}$ of $4 \mathrm{~N} \mathrm{NaOH}$, and the absorption at $620 \mathrm{~nm}$ was measured with an automated

A

A Experimental group

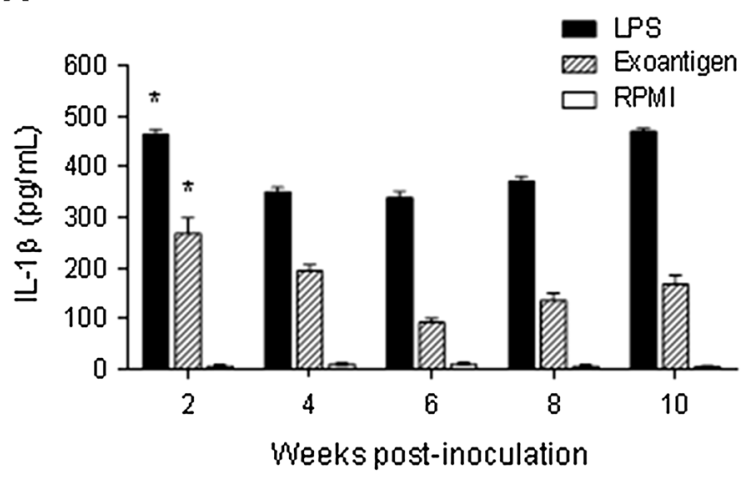

B

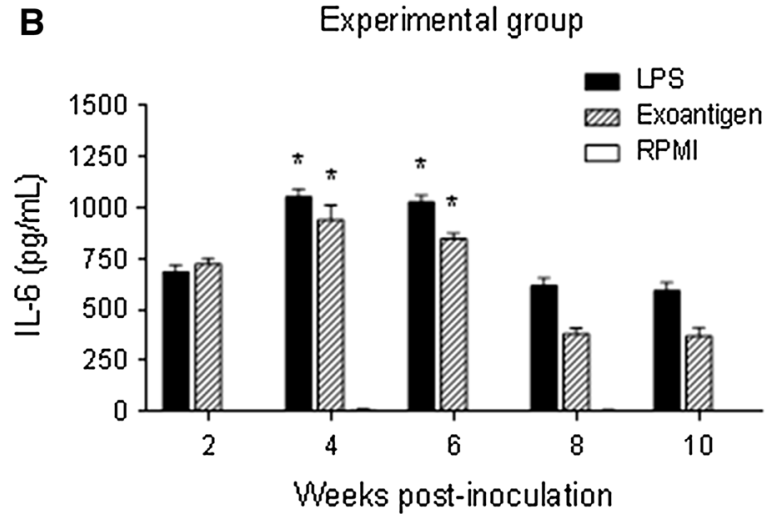

Fig. 5 IL-1 $\beta$ (a) and IL-6 (b) production by peritoneal macrophages of Swiss mice infected with S. schenckii. Peritoneal macrophage culture supernatants were obtained after 24-h stimulation with exoantigen (ExoAg) from S. schenckii,
Control group

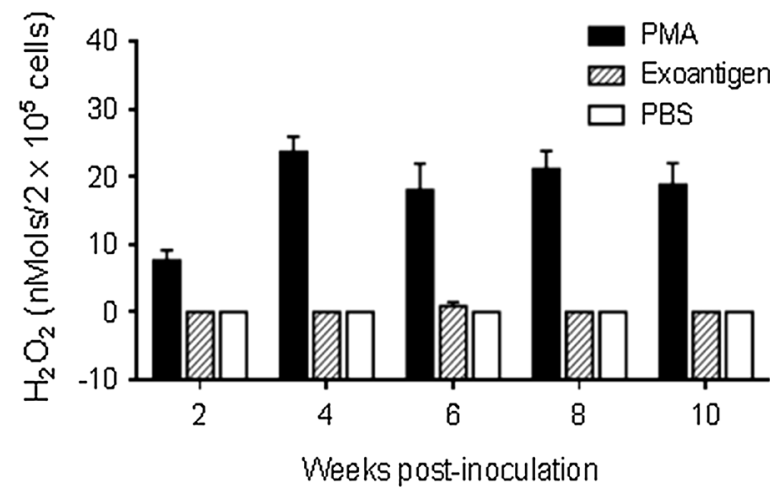

microplate reader. Results are reported as the mean $\pm \mathrm{SD}$ of triplicate observations. The level of significance was set at $p<0.005$ when $\mathrm{H}_{2} \mathrm{O}_{2}$ production by infected animals treated with ExoAg was compared with infected positive controls (PMA treated). Mean $\pm \mathrm{SD} ;{ }^{*} p<0.001$ (Tukey's test)
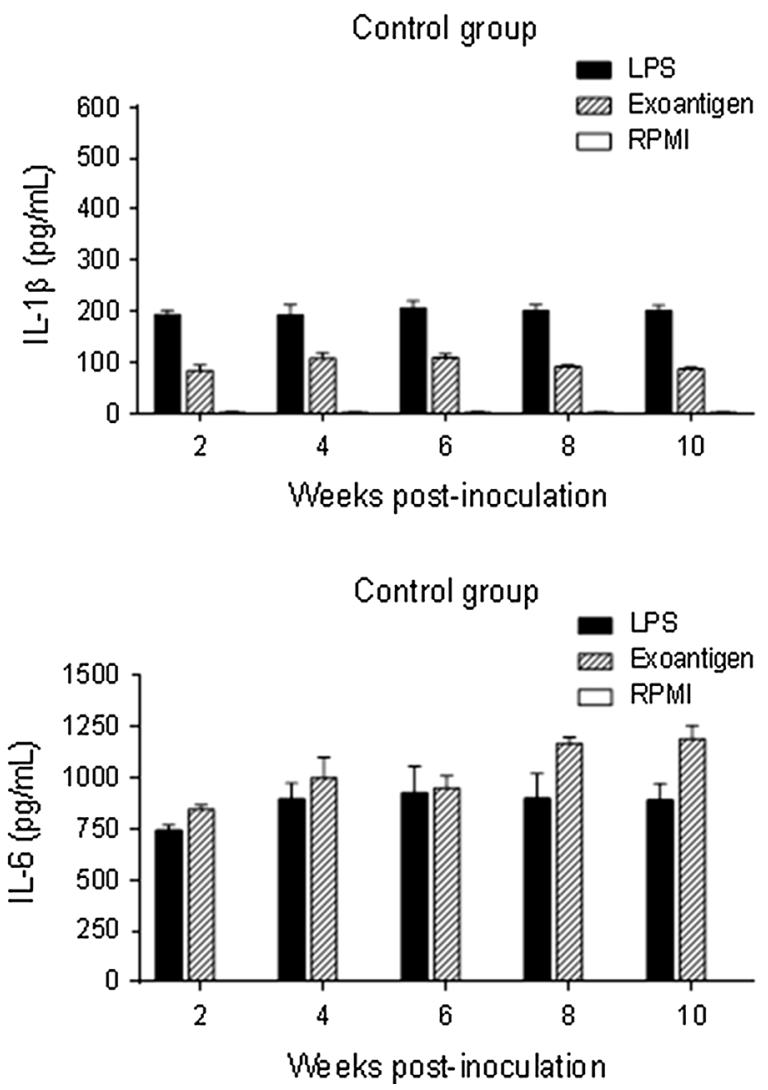

LPS or culture medium, and used in the IL-6, and IL- $1 \beta$ assay by ELISA at $450 \mathrm{~nm}$. Results are reported as the Mean $\pm \mathrm{SD}$; ${ }^{*} p<0.005$ regarding the lower data of the series (Tukey's test) 


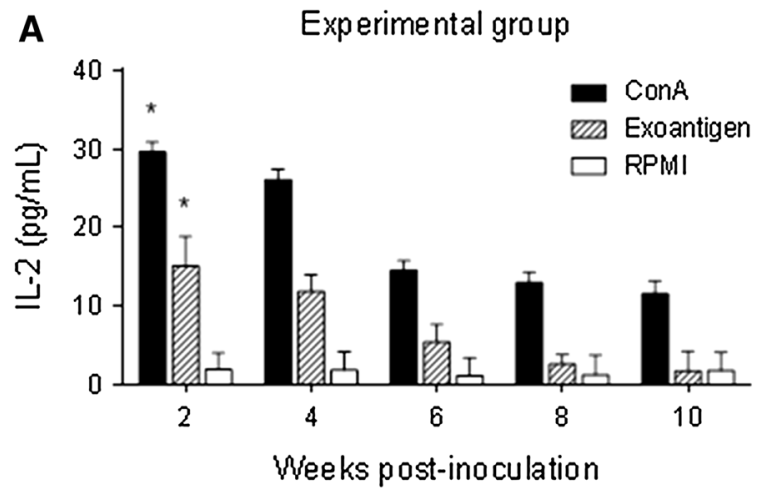

B Experimental group

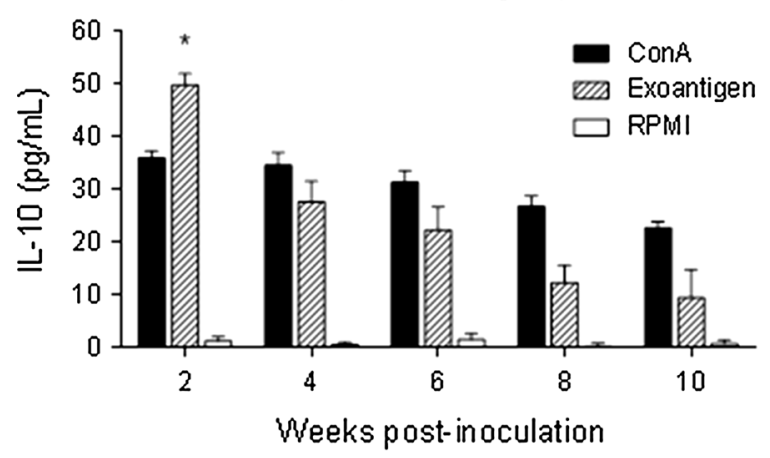

Fig. 6 IL-2 (a), and IL-10 (b) production in lymph nodes of Swiss mice infected with $S$. schenckii. Lymph nodes cells culture supernatants were obtained after 24-h stimulation with exoantigen (ExoAg) from S. schenckii, concanavalin A (ConA)

the inflammatory response such as IL-10, that inhibit the production of inflammatory cytokines by dendritic cells, macrophages, and $\mathrm{T}$ cells and indirectly IL-2 required for maintenance of regulatory $\mathrm{T}$ cells [27].

Our results reveal a strong production of $\mathrm{H}_{2} \mathrm{O}_{2}$ in the second week associated with low fungal burden in the spleen. Interestingly in the following four weeks, the endpoints are inverted with a drastic depression of $\mathrm{H}_{2} \mathrm{O}_{2}$ and a pick of fungal burden with a subsequent depletion after the fourth week. This pattern was associated with an increment in apoptotic peritoneal macrophages during the period of greatest fungal burden, and this seems to be due to the infectious process.

These results also reinforces the data from previous studies in our laboratory, in which similar pattern in the production of $\mathrm{H}_{2} \mathrm{O}_{2}$ was observed in cells from TLR-4-deficient mice cultured with ExoAg, in the same period [11].
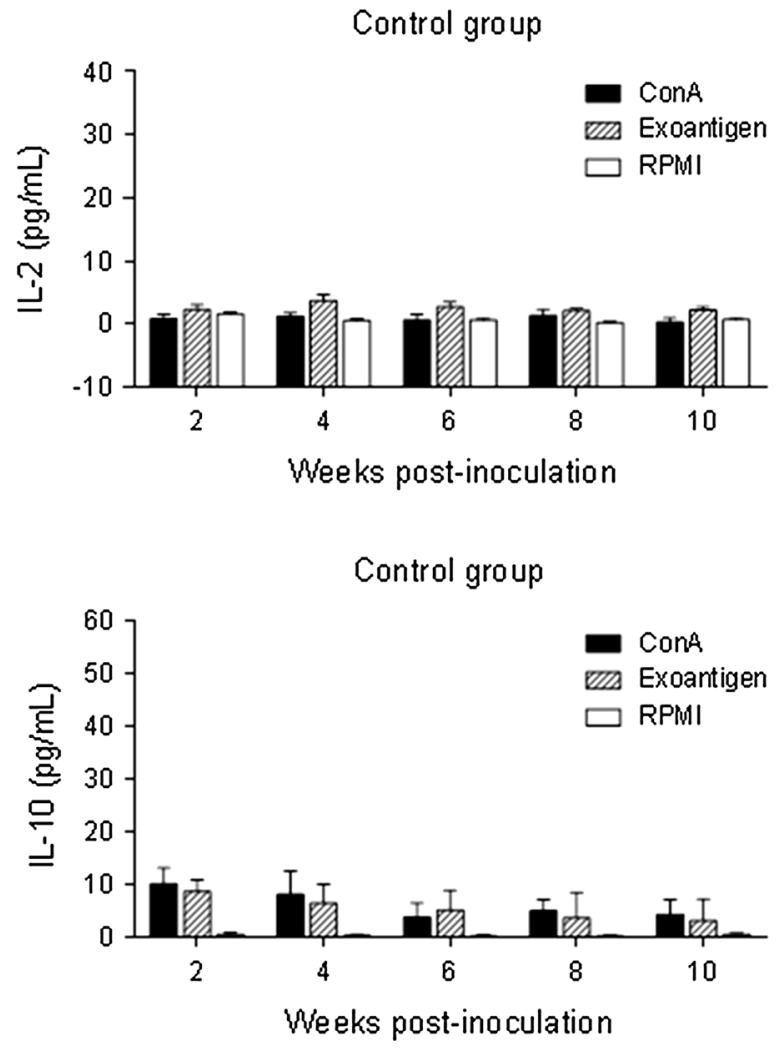

or RPMI-1640-C culture medium, and used in the IL-2, and IL10 assay by ELISA at $450 \mathrm{~nm}$. Results are reported as the Mean $\pm \mathrm{SD} ; * p<0.005$ regarding the lower data of the series (Tukey's test)

The ExoAg is continuously released throughout the infectious process [13]. Its ability to strongly stimulate the oxidative burst in the early phase of infection with ulterior withdrawal of $\mathrm{H}_{2} \mathrm{O}_{2}$ production, associated with the immunosuppressive activity of $\mathrm{H}_{2} \mathrm{O}_{2}$ for adaptive immunity $[23,24]$, may together facilities the spread of the fungus in the host organism if they are not completely eliminated during the first 2 week of infection. Fernandes et al. [25] used another model of sporotrichosis, inoculating intravenously $5 \times 10^{6}$ yeast and demonstrated that NO cause immunosuppression and it high production is detrimental in the defense against $S$. schenckii. Thus, $\mathrm{H}_{2} \mathrm{O}_{2}$ could be decisive in the early phase of infection, but detrimental in later phases. Certainly, excessive production of $\mathrm{NO}$ and $\mathrm{H}_{2} \mathrm{O}_{2}$, if they are unable to control de infection, can produce deleterious effects invoking a delay in developing acquired immunity through $\mathrm{T}$ cell unresponsiveness, favoring the microbial dissemination [27]. 
The reduction in IL-1 $\beta$ production by infected animal cells may also contribute to the impairment of fungal elimination. These results suggest that IL-1 $\beta$ production, but not IL-6, could have important role in the late phase of $S$. schenckii infection, contributing to the clearance of disease. In this way, Maia et al. [28] presented evidences of IFN- $\gamma$ production in the same period on S. schenckii infection, as evidence that a Th1 response is elicited in the late phase of infection and could be also responsible for the low fungal burden in this period. Other characteristic detected in this study was the presence of elevated of IL-2 that can be involved in the stimulation of the adaptive immune response, but also in the control of excessive inflammatory response mediated by lymphocytes $\mathrm{T}$ regulatory ( $\mathrm{T}$ reg). In addition, more evident was the high production of the anti-inflammatory IL-10, which can be associated with the apoptotic process induced by the fungal infection, as was observed in a murine model of fungal infection by Candida albicans [29]. This tendency to a transitory immunosuppressive profile observed between the fourth and sixth week may have favored the fungal load detected during this period.

In summary, our data suggest that IL- $1 \beta$, IL-2, and $\mathrm{H}_{2} \mathrm{O}_{2}$ may be important during the first weeks of $S$ schenckii infection, but after that, they are ineffective and even may favor the fungal dissemination due to the $\mathrm{H}_{2} \mathrm{O}_{2}$ immunosuppressive activity. The apoptosis associated with the infection can also be involved in the continue production of IL-10, contributing to the later transitory immune-suppressive setting. On the other hand, IL-1 $\beta$ (but not IL-6) may have important roles in the late phase of $S$. schenckii infection, contributing to the fungal clearance in conjunction with the specific mechanisms. Thus, the protective or deleterious role of these immune mediators, in vivo is complex, involving different factors such as: the time of the infection, the balance between pro and antiinflammatory and other mechanisms that even need to be unraveled. Our data also highlight a role of the ExoAg as an important fungal component directly involved in the host immune modulation, influencing the $S$. schenckii virulence.

Acknowledgments This work was supported by grants from the State of Sao Paulo Research Foundation (FAPESP) (Grants No. 2009/11442-9). Coordenação de Aperfeiçoamento de Pessoal de Nivel Superior (CAPES, Brazil): Foreigner Visiting Professor Program (Grant 07610130).

\section{Compliance with Ethical Standards}

Conflict of interest The authors declare that no competing interests exist.

\section{References}

1. Rodrigues AM, de Hoog S, de Camargo ZP. Emergence of pathogenicity in the Sporothrix schenckii complex. Med Mycol. 2013;51(4):405-12.

2. López-Romero E, del Reyes-Montes MR, Pérez-Torres A, Ruiz-Baca E, Villagómez-Castro JC, Mora-Montes HM, Flores-Carreón A, Toriello C. Sporothrix schenckii complex and sporotrichosis, an emerging health problem. Fut Microbiol. 2011;6(1):85-102.

3. Carlos IZ, Sgarbi DB, Placeres MC. Host organism defense by a peptide-polysaccharide extracted from the fungus Sporothrix schenckii. Mycopathologia. 1999;144:9-14.

4. Dickerson CL, Taylor RL, Drutz DJ. Susceptibility of congenitally athymic (nude) mice to sporotrichosis. Infect Immun. 1983;40:417-20.

5. Aarestrup FM, Guerra RO, Vieira BJ, Cunha RM. Oral manifestation of sporotrichosis in AIDS patients. Oral Dis. 2001;7:134-6.

6. Brown GD. Innate antifungal immunity: the key role of phagocytes. Annu Rev Immunol. 2011;29:1-21.

7. LeibundGut-Landmann S, Wüthrich M, Hohl TM. Immunity to fungi. Curr Opin Immunol. 2012;24:1-10.

8. de Negrini TC, Ferreira LS, Alegranci P, Arthur RA, Sundfeld PP, Maia DC, Spolidorio LC, Carlos IZ. Role of TLR-2 and fungal surface antigens on innate immune response against Sporothrix schenckii. Immunol Invest. 2013;42(1):36-48.

9. de Negrini TC, Ferreira LS, Arthur RA, Alegranci P, Placeres MCP, Spolidorio LC, Carlos IZ. Influence of TLR-2 in the immune response in the infection induced by fungus Sporothrix schenckii. Immunol Invest. 2014;43:370-90.

10. Sassá MF, Saturi AE, Souza LF, Ribeiro LC, Sgarbi DB, Carlos IZ. Response of macrophage Toll-like receptor 4 to a Sporothrix schenckii lipid extract during experimental sporotrichosis. Immunology. 2009;128(2):301-9.

11. Sassa MF, Ferreira LS, de Abreu Ribeiro LC, Carlos IZ. Immune response against Sporothrix schenckii in TLR-4deficient mice. Mycopathologia. 2012;174:21-30.

12. Gonçalves AC, Maia DC, Ferreira LS, Monnazzi LG, Alegranci $\mathrm{P}$, Placeres MC, Batista-Duharte A, Carlos IZ. Involvement of major components from Sporothrix schenckii cell wall in the caspase- 1 activation, nitric oxide and cytokines production during experimental sporotrichosis. Mycopathologia. 2015;179(1-2):21-30.

13. Carlos IZ, Sgarbi DB, Santos GC, Placeres MC. Sporothrix schenckii lipid inhibits macrophage phagocytosis: involvement of nitric oxide and tumour necrosis factor-alpha. Scand J Immunol. 2003;57(3):214-20.

14. Carlos IZ, Sassá MF, da Graça Sgarbi DB, Placeres MC, Maia DC. Current research on the immune response to experimental sporotrichosis. Mycopathologia. 2009;168(1): $1-10$.

15. Fernandes GF, dos Santos PO, Rodrigues AM, Sasaki AA, Burger E, de Camargo ZP. Characterization of virulence 
profile, protein secretion and immunogenicity of different Sporothrix schenckii sensu stricto isolates compared with $S$. globosa and $S$. brasiliensis species. Virulence. 2013;4(3):241-9.

16. Lowry OH, Rosebrough NJ, Farr AL, Randall RJ. Protein measurement with the Folin phenol reagent. J Biol Chem. 1951;193:265-75.

17. Pick E, Keisari Y. A simple colorimetric method for the measurement of hydrogen 404 peroxide by cells in culture. J Immunol Methods. 1980;38(1-2):161-70.

18. Pick E, Mizel D. Rapid microassay for the measurement of superoxide and hydrogen peroxide production by macrophages in culture using in automatic enzyme immunoassay reader. J Immunol Methods. 1981;46:211-26.

19. Téllez MD, Batista-Duharte A, Portuondo D, Quinello C, Bonne-Hernández R, Carlos IZ. Sporothrix schenckii complex biology: environment and fungal pathogenicity. Microbiology. 2014;160(Pt 11):2352-65.

20. Polonelli L, Morace G. Exoantigen Studies of Sporothrix schenckii, Ceratocystis minor, and Graphium penicilliodes cultures. J Clin Microbiol. 1982;15(3):362-5.

21. Alegranci P, de Abreu Ribeiro LC, Ferreira LS, de Negrini TC, Maia DC, Tansini A, Gonçalves AC, Placeres MC, Carlos IZ. The predominance of alternatively activated macrophages following challenge with cell wall peptidepolysaccharide after prior infection with Sporothrix schenckii. Mycopathologia. 2013;176(1-2):57-65.

22. Ferreira LS, Gonçalves AC, Portuondo DL, Maia DC, Placeres MC, Batista-Duharte A, Carlos IZ. Optimal clearance of Sporothrix schenckii requires an intact Th17 response in a mouse model of systemic infection. Immunobiology. 2015;220(8):985-92.
23. Takahashi A, Hanson MG, Norell HR, Havelka AM, Kono K, Malmberg KJ, Kiessling RV. Preferential cell death of CD8+ effector memory (CCR7-CD45RA-) T cells by hydrogen peroxide-induced oxidative stress. J Immunol. 2005;174(10):6080-7.

24. Lee M, Yea SS. Hydrogen peroxide inhibits the immune response to lipopolysaccharide by attenuating signaling through c-Jun $\mathrm{N}$-terminal kinase and p38 associated with protein kinase C. Immunopharmacology. 2000;48(2): 165-72.

25. Fernandes KSS, Helal EN, Brito MMS, Silva JS, Cunha FQ, Barja-Fidalgo C. Detrimental role of endogenous nitric oxide in host defence against Sporothrix schenckii. Immunology. 2008;123:469-79.

26. Eisenstein TK. Implications of Salmonella-induced nitric oxide (NO) for host defense and vaccines: NO, an antimicrobial, anti-tumor, immunosuppressive and immunoregulatory molecule. Microbes Infect. 2001;3:1223-31.

27. de la Rosa M, Rutz S, Dorninger H, Scheffold A. Interleukin-2 is essential for CD4+ CD25+ regulatory $\mathrm{T}$ cell function. Eur J Immunol. 2004;34:2480-8.

28. Maia DC, Sassa MF, Placeres MC, Carlos IZ. Influence of Th1/Th2 cytokines and nitric oxide in murine systemic infection induced by Sporothrix schenckii. Mycopathologia. 2006;161(1):11-9.

29. Gasparoto TH, Gaziri LC, Burger E, de Almeida RS, Felipe I. Apoptosis of phagocytic cells induced by Candida albicans and production of IL-10. FEMS Immunol Med Microbiol. 2004;42(2):219-24. 